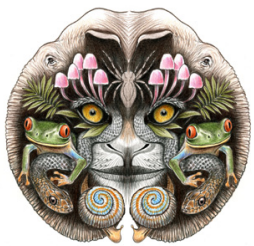

ISSN

Online 0974-7907

Print 0974-7893

OPEN ACCESS

\title{
PHOTOGRAPHIC ESTIMATION OF ROOSTING DENSITY OF GEOFFROY'S ROUSETTE FRUIT BAT ROUSETTUS AMPLEXICAUDATUS (CHIROPTERA: Pteropodidae) at Monfort Bat CaVe, Philippines
}

\author{
Ela-Sita Carpenter ${ }^{1}$, Rai Gomez ${ }^{2}$, David L. Waldien ${ }^{3}$ \& Richard E. Sherwin ${ }^{4}$
}

${ }^{1,4}$ Christopher Newport University, Department of Organismal \& Environmental Biology, 1 Avenue of the Arts, Newport News, Virginia 23606, USA

${ }^{2}$ Philippine Eagle Center, Malagos, Davao City 8000, Philippines ${ }^{3}$ Bat Conservation International, P.O. Box 162603, Austin, TX 78716-2603, USA ${ }^{1}$ elasita@gmail.com, ${ }^{2}$ rksgomez@gmail.com, ${ }^{3}$ dwaldien@batcon.org (corresponding author), ${ }^{4}$ rsherwin@cnu.edu

Abstract: Conservation and management of bats requires reliable and repeatable data regarding the size and patterns of variation in size of bat colonies. Counts and densities calculated via photography have proven more accurate and repeatable than visual counts and ocular estimates. Unfortunately, the potential of photography to investigate the size of a bat colony and roost density has rarely been explored. In the summer of 2006, a colony of Geoffroy's Rousette Fruit Bat, Rousettus amplexicaudatus, was photo-documented in the Monfort Bat Cave, in the Island Garden City of Samal, Davao de Norte, Mindanao, Philippines. We selected 39 images to develop roost density estimates. Mean ( \pm SE) roosting density was $403 \pm 167.1$ bats $/ \mathrm{m}^{2}$ and $452.3 \pm 168.8 \mathrm{bats} / \mathrm{m}^{2}$ on the walls and ceiling of the cave, respectively; densities were not significantly different from each other $(P=0.38)$. Based on these standardized data, we estimate that the initial $100 \mathrm{~m}$ of the cave contained 883,526 bats. Ultimately, this photographic technique can be used to develop a statistical approach which involves repeatable estimates of colony size for Geoffroy's Rousette Fruit Bats at Monfort Cave and will enhance ongoing monitoring activities throughout this species range.

Keywords: Cave, count data, Geoffroy's Rousette Fruit Bat, monitoring bats, population estimates.
Geoffroy's Rousette Fruit Bat Rousettus amplexicaudatus is a medium-sized (64-106 g, forearm length 80-92 mm; Heaney et al. 2010) fruit bat (Family: Pteropodidae) that can be found in areas reaching from Thailand to the Solomon Islands and throughout the Philippines (Heaney et al. 1998). It is one of the 79 species of bats confirmed to occur in the Philippines and is considered to be relatively common throughout its range (Ingle \& Heaney 1992; Heaney et al. 1998, 2010). The species is abundant in lowland agricultural areas and is considered to be a cave-obligate as all known colonies appear restricted to subterranean features (Heaney et al. 2002). Typically, R. amplexicaudatus roosts in colonies ranging from 2,000 to 100,000 (Mould 2012). While the species is thought to be relatively stable throughout its range (having an IUCN 'Least Concern'

DOI: http://dx.doi.org/10.11609/JoTT.o3522.5838-44 | ZooBank: urn:Isid:zoobank.org:pub:C2EA85AA-8B52-4EBC-927D-FC3B94975BD4

Editor: Jodi L. Sedlock, Lawrence University, Appleton, USA

Date of publication: 26 June 2014 (online \& print)

Manuscript details: Ms \# 03522 | Received 09 February 2013 | Final received 26 April 2014 | Finally accepted 29 May 2014

Citation: Carpenter, E.-S., R. Gomez, D.L. Waldien \& R.E. Sherwin (2014). Photographic estimation of roosting density of Geoffroy's Rousette Fruit Bat Rousettus amplexicaudatus (Chiroptera: Pteropodidae) at Monfort Bat Cave, Philippines. Journal of Threatened Taxa 6(6): 5838-5844; http://dx.doi.org/10.11609/JoTT. 03522.5838-44

Copyright: (c) Carpenter et al. 2014. Creative Commons Attribution 4.0 International License. JoTT allows unrestricted use of this article in any medium, reproduction and distribution by providing adequate credit to the authors and the source of publication.

Funding: Bat Conservation International; Beneficia Family Foundation; Christopher Newport University; Disney Worldwide Conservation Fund; Monfort Bat Cave \& Conservation Foundation.

Competing Interest: The authors declare no competing interests.

Acknowledgements: This study was made possible through the generous support of N. Monfort and the Monfort Bat Cave \& Conservation Foundation. The authors thank Jamin Valentine for his revision and editing efforts for manuscript submission and Jim Kennedy for the diagram of the external openings of the Monfort Bat Cave. We also thank Bat Conservation International, Beneficia Family Foundation, Christopher Newport University and Disney Worldwide Conservation Fund for providing funding. Photographs used in this study are copyright M.D. Tuttle, courtesy of Bat Conservation International.
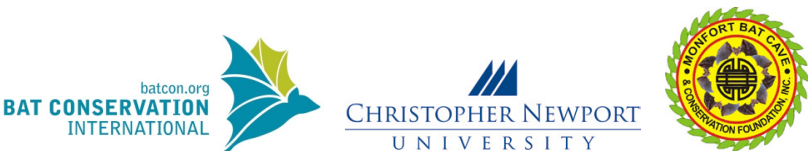
status: Csorba et al. 2008), some colonies are subject to intense hunting (Utzurrum 1992; Scheffers et al. 2012), and anthropogenic pressures at cave roosts throughout its range have resulted in the abandonment of many historically occupied sites. For example, personal observations from Mindanao by several of the authors (DLW, RES, RG) found many of the historical roost sites for the species to be largely abandoned.

Throughout much of the world large colonies of cave-dwelling bats are in jeopardy; they have declined in number or have been extirpated due to direct mortality (e.g., hunting), or indirectly through human disturbance, inappropriate guano mining, and hunting of the bats for food (Utzurrum 1992; Mickleburgh et al. 2009). Reliable, quantitative information on colony size over time is fundamental to the conservation and management of bats. It provides critical insight into colony trends (O'Shea \& Bogan 2003; Walsh et al. 2003) and the effectiveness of management actions. Without these monitoring data, researchers and managers may overlook dramatic changes in colony sizes, particularly those masked in large colonies where viewers are quickly overwhelmed by the sheer number of bats.

Many methods have been used to estimate colony size by counting bats as they exit roosts (Kunz 2003; McCracken 2003; O'Shea \& Bogan 2003). When appropriate tools are available, and if colonies are relatively small or restricted to a single exit, bats can be manually counted by hand tallying during actual outflights, or by recording out-flights and later developing estimates of colony sizes by analyzing video data (Thomas \& LaVal 1988; Fleming et al. 2003; McCracken 2003). However, without the use of highly sophisticated and often costly equipment, which can record outflights and allow for intensive post processing, these exit surveys usually prove to be unreliable, unrepeatable, and of little value for long term monitoring of colony trends (Kunz 2003). These problems are greatly exacerbated when dealing with species that form large colonies that number in the tens to hundreds of thousands (Kunz 2003).

When properly conducted, external surveys are generally preferable to internal evaluations as they minimize disturbance to bats within the roost (Thomas \& LaVal 1988). Unfortunately, external techniques are not always feasible. All bats may not exit the roost on any given night, the openings to the roost may not be conducive to monitoring, the colony may exit through multiple openings that are not readily monitored, or the cost of equipment necessary for reliable exit surveys may be prohibitive (Thomas \& LaVal 1988). In these cases, site-specific internal census techniques are needed to reliably document colony size.

The potential of photography to investigate colony size and density has not been fully explored. When photographic estimation has been used in the past, survey techniques described often lack the amount of detail required to replicate it in later studies. Counts and densities calculated via photography have been shown to be more accurate and easier to replicate than visual counts and estimates (Meretsky et al. 2010). Photographic counts can also be conducted in low-light situations; thus reducing the amount of disturbance to roosting bats.

Estimating colony size from the surface area covered by roosting bats provides a repeatable technique for large colonies where counting bats is not feasible (Thomas \& LaVal 1988; Tuttle 2003), although indiscriminately applying a standard roost density to all roost surfaces is inappropriate as it does not account for variability in the roost surfaces and roost density (Kunz 2003). Photography has also been used to estimate or confirm roost density, numbers of bats in a roost, and the area covered by roosting bats (Constantine 1967; Tuttle 2003; Meretsky et al. 2010). Unfortunately, reliable density estimates are not available for many of the world's major colonial roosting species, including Geoffroy's Rousette Fruit Bat. Published accounts of photographic density estimates to date are only available for a few microchiropteran species-Myotis sodalis (Tuttle 2003), Meretsky et al. (2010), Tadarida brasiliensis (Constantine 1967), and Myotis grisescens (Tuttle 2003). Further development of reliable speciesspecific density estimates will allow landowners, conservation biologists, and resource managers a means to monitor major bat colonies and trends, and evaluate colony responses to disturbance, management, and restoration efforts.

More accurate and precise estimates of colony size and seasonal dynamics are needed to effectively conserve and manage key roosts. In this study, we used digital photography to develop roost density estimates for a colony of Geoffroy's Rousette Fruit Bat in the Philippines and discuss its application for estimating colony size and trends.

\section{MATERIALS AND METHODS}

The Monfort Bat Cave is located on the Island Garden City of Samal, Davao del Norte, Philippines $\left(7.0500^{\circ} \mathrm{N} \&\right.$ $\left.125.7333^{\circ} \mathrm{E}\right)$. The cave is located on privately owned property and has been protected by the Monfort family for nearly 100 years. It is a relatively small cave, 


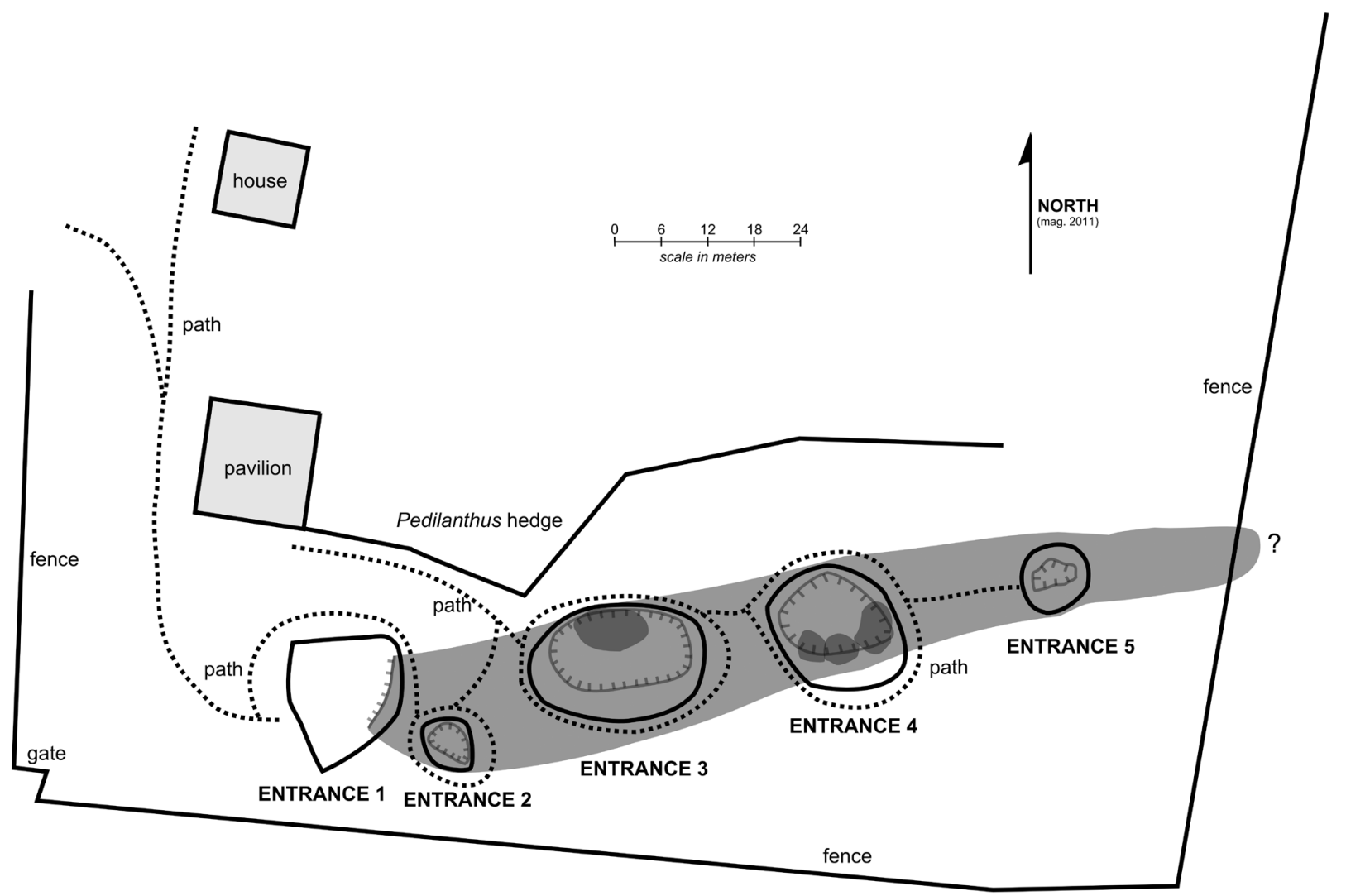

Figure 1. Map of the Monfort Bat Cave depicting one horizontal entrance and four vertical sinkhole entrances. The gray shaded area represent the approximate cave dimensions. Image courtesy of Bat Conservation International.

approximately $150 \mathrm{~m}$ in length, with irregular internal dimensions throughout, averaging roughly $3 \mathrm{~m}$ high and $5 \mathrm{~m}$ wide, and is situated within $200 \mathrm{~m}$ of the Davao Gulf. The cave is accessible through a horizontal entrance and four vertical sinkhole entrances; bats routinely exit the cave through all five openings (Fig. 1). Since its initial use by bats in the 1940s, local observations indicate that the colony size has been increasing steadily. The cave is now so heavily used by bats that virtually all surfaces on the cave walls and ceilings are covered with large numbers of roosting bats, including areas exposed to full sunlight in the sinkhole entrances. Furthermore, the bats roost on nearly every vertical surface from the floor to the ceiling, fill the voids under large breakdown boulders, and have even begun to roost outside the cave entrance (Images 1-3).

Field methods: A team of two entered the Monfort Bat Cave, either through the main horizontal entrance or the third vertical entrance from mid-morning to early afternoon on June 5, 6, and 8, 2006, to photographically document the colony, taking care to minimize disturbance. Although bats flew upon entry, most remained in the roost unless closely or quickly

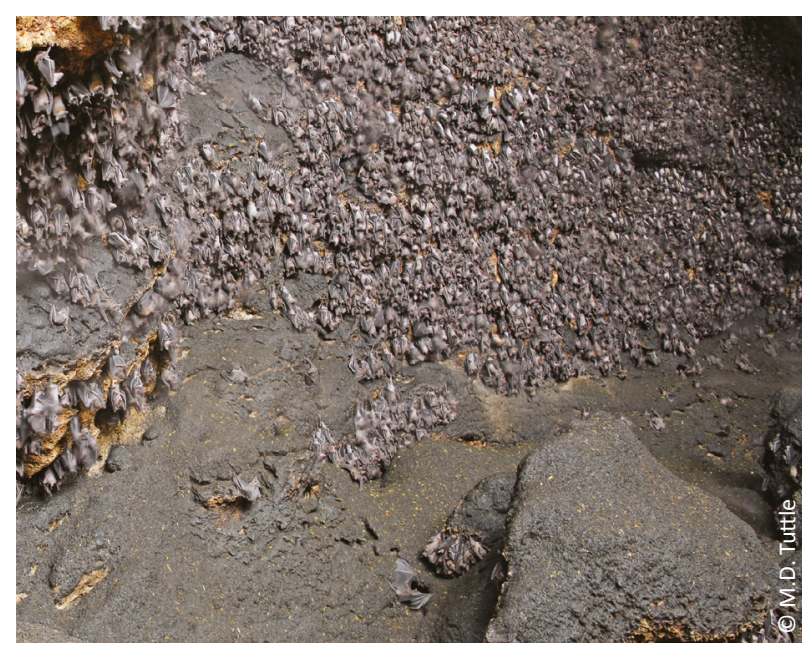

Image 1. Geoffroy's Rousette Fruit Bats Rousettus amplexicaudatus roost over much of the wall and even under rocks on the cave floor.

approached (typically within two meters). The simple nature of the cave and light from the series of overhead sinkhole entrances allowed us to identify areas where the bats roosted regardless of our location and helped to minimize disturbance. Images were taken with a 


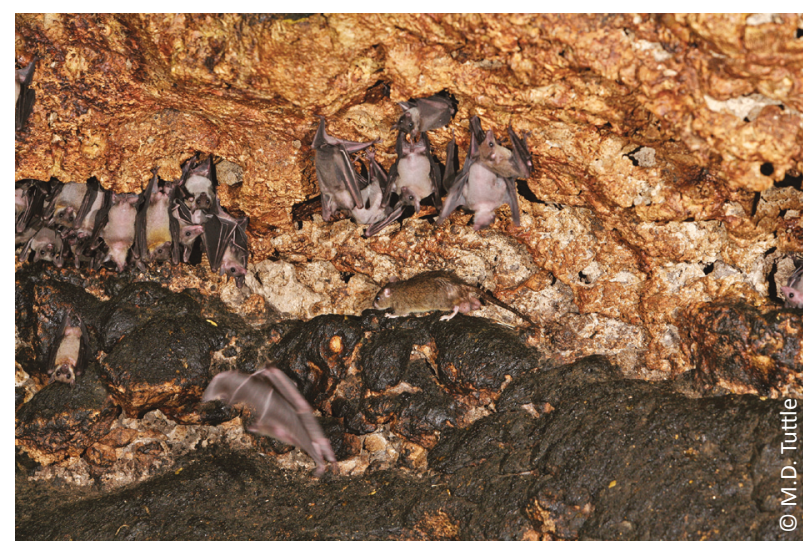

Image 2. Geoffroy's Rousette Fruit Bats Rousettus amplexicaudatus

Canon 5D digital camera and various lenses including a Canon 70-200 mm/F2.8 lens, a Canon 28-135 mm/F3.55.6 lens, and a Canon 28-70 mm lens from distances of up to $10 \mathrm{~m}$. Images were taken at non-random locations throughout the cave. The front of the cave was photographed on June 5 , the middle of the cave on June 6 , and the rear of the cave on June 8 .

Selection of photographs for analysis: We selected 39 images for estimating roosting density of Geoffroy's Rousette Fruit Bats from several hundred digital images of roosting bats in the Monfort Bat Cave. This sample represented all images of sufficient resolution, orientation and quality to calculate roost density. Images where disturbances occurred were not included in the study. We assumed we had independent samples as images were obtained from various locations within the cave system. We excluded sequential images unless they clearly represented different roost areas based on cave morphology. We chose the largest area available from each of the 39 images selected to analyze and calculate roost density (areas ranged from 0.07-4.28 $\mathrm{m}^{2}$ ). We used bats roosting on moderately flat ceiling or wall surfaces in order to facilitate accurate counts. We assumed that images represented the range of roost densities found in the cave under relatively undisturbed conditions.

Analysis of images: We measured inter- and postorbital distance $(\mathrm{mm})$ on 26 preserved Geoffroy's Rousette Fruit Bat specimens in in the University of the Philippines, Mindanao collection (one adult male, three adult females, 15 juvenile males and seven juvenile females). We calculated average post-orbital distances for adult females and juveniles as there is sexual dimorphism in the species and juveniles are smaller than adults. We also calculated a weighted average inter- and post-orbital distance measure as the Monfort Bat Cave colony includes male and female adult and juvenile bats.

Within each image, we marked and counted all

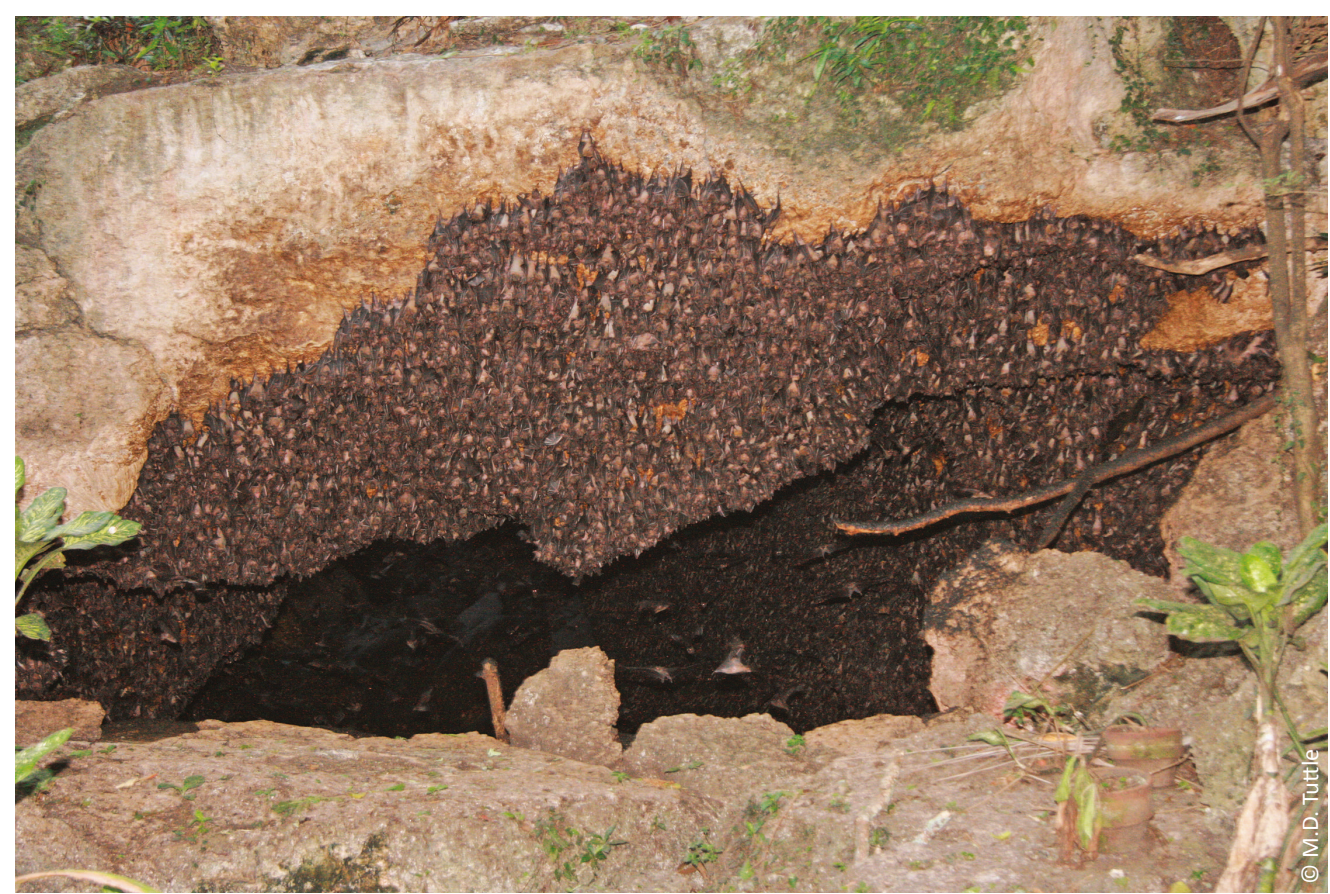

Image 3. Geoffroy's Rousette Fruit Bats Rousettus amplexicaudatus are protected at the Monfort Bat Cave and the competition for roost space is so great that the bats routinely roost outside the horizontal entrance in broad daylight. 


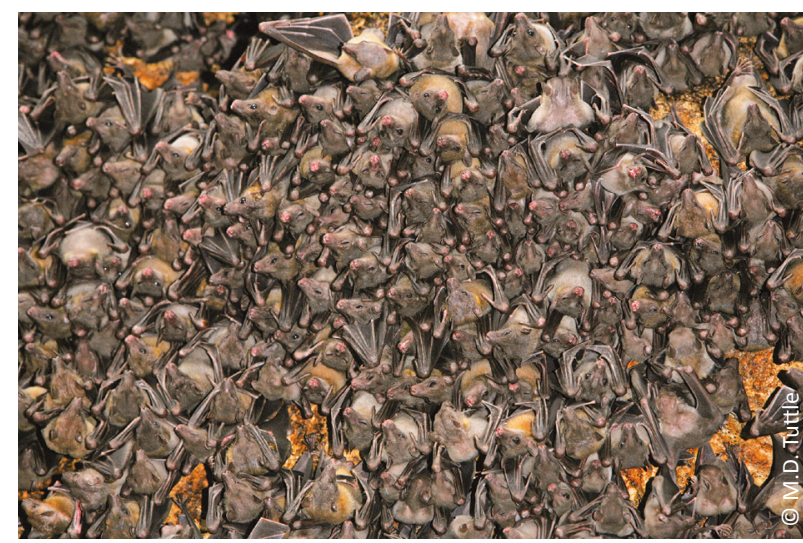

Image 4. Geoffroy's Rousette Fruit Bats Rousettus amplexicaudatus roosts in varied densities at the Monfort Bat Cave. The center of this image is an example of a higher density where the heads of the bats are mostly visible. Lower roost densities are visible at the periphery of the image where shoulders, and chests of bats, and portions of the cave wall are visible.

individual bats showing at least half of their bodies within the image; these data were independently verified by having multiple individuals sample each image and develop individual count data. In rare cases where we found discrepancies, we revisited images, determined the cause of the disparity and corrected accordingly until all analysts reached the same count. Generally, we selected 2-5 bats with heads oriented perpendicular to the image by which the post-orbital view was unobstructed. Because the sex and age of the bats could not be consistently identified, we applied the weighted average of the intra-orbital and postorbital distances to all images in order to calculate the area represented within each image. We calculated an average roost density for the colony based on all 39 images used.

The images were then categorized as either a wall or ceiling image based on the angle at which the bats appeared to be hanging. If it was unclear, the image was marked as unknown and not included in the statistical analysis. Average density was then calculated for the ceiling and wall and the two were analyzed using a t-test to determine if density was significantly different on either substrate.

We have not been able to produce a survey quality map of this cave because of the intense and protracted reproductive activity of the bats in this site. However, we have been able to develop estimates of surface areas of the initial $100 \mathrm{~m}$ of the cave. We used surface areas to develop estimates of the total number of bats roosting in this portion of the cave by extrapolating density estimates for ceilings and walls across the total available roosting surface area of each.

\section{RESULTS}

The weighted mean $( \pm S E)$ intra-orbital and postorbital distance of the 26 Geoffroy's Rousette Fruit Bat specimens was $10.6 \pm 0.90 \mathrm{~mm}$ and $17.41 \pm 0.90 \mathrm{~mm}$, respectively. The juvenile specimen's intra-orbital and post-orbital distance were $10.4 \pm 0.49 \mathrm{~mm}$ and $17.0 \pm 1.0$ $\mathrm{mm}$, respectively. Adult female specimen's intraorbital and post-orbital distance were $11.0 \pm 0.76 \mathrm{~mm}$ and $16.5 \pm 1.34 \mathrm{~mm}$, respectively. Because there was only one adult male specimen, a mean intra-orbital and post-orbital distance could not be calculated. Of the 39 images, 23 images were of bats roosting from the cave's ceiling and 16 images were of bats roosting from the cave wall.

We applied the weighted intra-orbital and postorbital average to scale each image. Area within the images varied from $0.07-4.28 \mathrm{~m}^{2}$, with a mean photo area of $0.60 \pm 0.75 \mathrm{~m}^{2}$. Mean $( \pm \mathrm{SE}$ ) roosting densities of the cave wall $\left(403.0 \pm 167.0 \mathrm{~m}^{2}\right.$, range $=151.0-818.0$ bats $/$ $\left.\mathrm{m}^{2}\right)$ and ceiling $\left(452.3 \pm 168.8 \mathrm{~m}^{2}\right.$, range $=89.0-750.0$ bats $/ \mathrm{m}^{2}$ ) were not significantly different from each other ( $\mathrm{n}_{1}=16, \mathrm{n}_{2}=23, \mathrm{t}=2.03, P=0.38$ ). Therefore, we calculated an overall average for all 39 images (427.9 \pm 168.0 bats/ $\mathrm{m}^{2}$, range $=89.0-818.0$ bats $/ \mathrm{m}^{2}$ ). Image 4 displays a photograph that represents a range of roosting densities observed within the cave.

For determining the number of bats roosting in the mapped portions of the cave, we developed an estimate of $265 \mathrm{~m}^{2}$ of ceiling and $1800 \mathrm{~m}^{2}$ of vertical roosting surface (i.e., wall, edges of fallen slabs). As there was no significant difference between densities between walls and caves, we combined these areas to develop an estimate of $2,065 \mathrm{~m}^{2}$ of roosting surface. Based on this area, combined with the average density of 427.9 bats/ $\mathrm{m}^{2}$ we estimate that 883,526 bats were roosting in the initial $100 \mathrm{~m}$ of the cave.

\section{DISCUSSION}

Although developing estimates of colony sizes from extrapolating densities across surface area is not new or novel, this study represents an initial attempt to develop roosting density of Geoffroy's Rousette Fruit Bat from which error can be estimated. As such, this technique provides a mechanism to more effectively monitor colony size for the species throughout its range. Given that the Monfort Cave bat colony is larger than is typical for this species, the average roost density of 427.9 bats $/ \mathrm{m}^{2}$ that we measured may be higher than other Geoffroy's Rousette colonies in the Philippines. 
However, the techniques used to develop these estimates can be readily replicated at other roost sites and it is quite possible that individual colonies have unique densities that reflect roost structure, timing of occupancy, etc. This study varies from previous roosting density studies, which focused on determining the densities of microchiropterans, usually during hibernation (Gray Myotis Myotis grisescens 538-2,695 bats/ $\mathrm{m}^{2}$ and Indiana Myotis M. sodalis 3,228-5,208 bats/ $\mathrm{m}^{2}$ : Tuttle 2003; and 0-6,200 bats $/ \mathrm{m}^{2}$, Indiana Myotis: Meretsky et al. 2010). Constantine (1967) estimated the density of Mexican Free-tail Bats in Carlsbad Caverns to be approximately 3,228 bats $/ \mathrm{m}^{2}$ during their peak (April to October). In many of these studies, however, the bats were in distinct clusters whereas individuals in this colony of Geoffroy's Rousette Fruit Bats completely covered virtually all roost surfaces within the cave, and in some cases, surfaces immediately outside of the cave. Additionally, R. amplexicaudatus is much bigger than microchiropterans (forearm length 80-92 mm: Heaney et al. 2010).

Bat densities within the Monfort Cave varied greatly across the ceiling and the walls. This heterogeneous distribution may be due to irregularities on the cave walls, time of day or season. For example, hibernating Myotis have been found to roost in greater densities on the most uneven surfaces within a cave roost (Tuttle 2003). While we were not able to map the internal structural variation of the cave precisely, the Monfort cave walls were highly variable as breakdown (internal collapses) produced many undulations, while past rockfalls inside the cave had produced smaller domes within the cave, and erosion from the vertical openings produced finer scale variation on cave walls. All of these variants may have influenced bat density. Furthermore, Meretsky et al. (2010) noted that density within a cluster of Indiana Myotis varied with distance from the edge of the cluster, although this was not often encountered in the Monfort Bat Cave as the bats generally roosted continuously across the walls and ceilings; more discrete clusters were observed roosting on breakdown where roost surfaces were more discrete. Moreover, ongoing video recording research by one of the authors (RES) at the cave revealed that densities appear to change throughout the day as individuals shift towards the openings at the onset of dusk. This behavior would expand the area of roosting coverage while concurrently dropping the density of bats per unit area within some areas of the roost (far from the exit) and increasing the density near the exit. This potential influence of circadian cycles on density and roosting position is an often overlooked dynamic of roosting bats.

Finally, the season in which the survey was undertaken may influence the density estimates. We conducted our study during June when Geoffroy's Rousette Fruit Bats had suckling and have newly weaned pups. Given this, our density estimates may be higher than if they were taken during a non-reproductively active season. Reproduction in Geoffroy's Rousette Fruit Bat is considered to be highly synchronous with females giving birth twice each year (March/April and August/ September), which coincides with the peak of flowering and fruit ripening in the surrounding areas (Heideman \& Utzurrum 2003). Additionally, primigravidae often have their first offspring between these two periods (June/July) [around the time the photos were taken] and juvenile bats may roost at much greater densities (Thomas \& LaVal 1988). Therefore, breeding patterns should be clearly understood when attempting to extrapolate colony size from photographicallydetermined density estimates.

There is no known map for the Monfort Cave and the abundance of bats in the cave during our survey made it impossible to develop a very accurate map during the surveys. As a result, the location of each photograph was relatively imprecise. The location of many images had to be approximated following our internal surveys, resulting in several images not being readily identified as wall or ceiling; thus, reducing the effective sample size of data available for final analysis. This also means that in some cases, we might have mistakenly identified areas as wall when they were in fact ceiling images and vice versa. Subsequent photographic surveys would benefit from a more detailed documentation of each photograph's location.

While much effort was made to minimize disturbance to roosting bats during these surveys, the narrowness of the cave and size of the colony likely resulted in some localized adjustments in densities. We attempted to compensate for this by taking images of bats from great distances. However, the movement of bats while surveying may have led to lower or higher than normal density estimates in some photos, especially with the images taken towards the end of the survey and/or deeper in the cave.

Despite the adjustments of bats to our presence and associated changes in densities, this remained the best technique for estimating colony density at this particular site. The cave has five different openings from which bats exit, making it difficult to accurately count bats as they depart to estimate the colony size. Additionally, our ongoing research at the site reveals that many bats 
remain in the cave each night and that exiting patterns of bats (timing and intensity of departure through each opening) varies nightly in response to localized disturbance. This combination of factors makes counts from exit surveys at this site particularly problematic.

While specific attributes of this cave made it difficult to produce a complete estimate of colony size, our attempt to develop a numerical count for the mapped portions of the cave will still provide important information. Firstly, this technique provides a simple template that may be easily replicated by other researchers, who can determine for themselves its precision and accuracy. Secondly, repeated photographic population estimates over time at the Monfort Cave can be used to monitor changes in colony size and health and inform management decisions. In conducting this research we learned some valuable lessons that might be of value to those who apply photographic techniques for estimating cave bat populations. Specifically, we recommend that researchers establish clear, repeatable protocols that ensure collection of standardized, repeatable data (i.e., time of day, duration of internal survey, and location of data collection points), and include sufficient images from various roosting surfaces so that potential variation in roosting densities can be statistically evaluated.

\section{REFERENCES}

Csorba, G., G., Rosell-Ambal \& N. Ingle (2008). Rousettus amplexicaudatus. In: IUCN 2013. IUCN Red List of Threatened Species. Version 2013.2. <www.iucnredlist.org>. Downloaded on 07 June 2014.

Fleming, T.H., T. Tibbits, Y. Petryszyn \& V. Dalton (2003). Current status of pollinating bats in southwestern North America, pp. 63-68. In: O'Shea, T.J. \& M.A. Bogan (eds.). Monitoring Trends in Bat Populations of the United States and Territories: Problems and Prospects. U.S. Geological Survey Information and Technology Report, Fort Belvoir, United States, 274pp.

Heaney, L.R., D.S. Balete, M.L. Dolar, A.C. Alcala, A.T.L. Dans, P.C. Gonzales, N.R. Ingle, M.V. Lepiten, W.L.R. Oliver, P.S. Ong, E.A. Rickart, B.R. Tabaranza, Jr. \& R.C.B. Utzurrum (1998). A synopsis of the mammalian fauna of the Philippine Islands. Fieldiana Zoology New Series (88): 1-61.

Heaney, L.R., M.L. Dolar, D.S. Balete, J.A. Esselstyn, E.A. Rickart \& J.L. Sedlock (2010). Synopsis of Philippine Mammals: Rousettus amplexicaudatus <http://archive.fieldmuseum.org/philippine mammals/species_order/SP_210.asp>. On-line version dated 2010.

Heideman, P.D. \& R.C. Utzurrum (2003). Seasonality and synchrony of reproduction in three species of nectarivorous Philippines bats. BMC Ecology 3: 11. Published online Nov 21, 2003; http://dx.doi. org/10.1186/1472-6785-3-11

Ingle, N.R. \& L.R. Heaney (1992). A key to the bats of the Philippine Islands. Fieldiana Zoology (69): 1-44.

Kunz, T.H. (2003). Censusing bats: challenges, solutions, and sampling biases. pp. 9-20. In: O'Shea, T.J. \& M.A. Bogan (eds.). Monitoring Trends in Bat Populations of the United States and Territories: Problems and Prospects. U.S. Geological Survey Information and Technology Report, Fort Belvoir, United States, 274pp.

Meretsky, V.J., V. Brack, Jr., T.C. Carter, R. Clawson, R.R. Currie, T.A. Hemberger, C.J. Herzog, A.C. Hicks, J.A. Kath, J.R. MacGregor, R.A. King \& D.H. Good (2010). Digital photography improves consistency and accuracy of bat counts in hibernacula. Journal of Wildlife Management 74(1): 166-173; http://dx.doi.org/10.2193/2008-306

McCracken, G.F. (2003). Estimates of population sizes in summer colonies of Brazilian Free-tailed Bats (Tadarida brasiliensis). pp. 21-30. In: O'Shea, T.J. \& M.A. Bogan (eds.). Monitoring Trends in Bat Populations of the United States and Territories: Problems and Prospects. U.S. Geological Survey Information and Technology Report, Fort Belvoir, United States, 274pp.

Mould, A. (2012). Cave bats of the central west coast and southern section of the Northwest Panay Peninsula, Panay Island, the Philippines. Journal of Threatened Taxa 4(11): 2993-3028; http:// dx.doi.org/10.11609/JoTT.o3104.2993-3028

O'Shea, T.J. \& M.A. Bogan (eds). (2003). Monitoring Trends in Bat Populations of the United States and Territories: Problems and Prospects. U.S. Geological Survey Information and Technology Report, Fort Belvoir, United States, 274pp.

Scheffers, B.R., R.T. Corlett, A. Diesmos \& W.F. Laurance (2012). Local demand drives a bushmeat industry in a Philippine forest preserve. Tropical Conservation Science 5(2): 133-141.

Thomas, D.W. \& R.K. LaVal (1988). Survey and census methods, pp. 77-90. In: Kunz, T.H. (ed.). Ecological and Behavioral Methods for the Study of Bats. Smithsonian Institution Press, Washington D.C., United States, 533pp.

Tuttle, M.D. (2003). Estimating population sizes of hibernating bats inn caves and mines. pp. 31-40. In: O’Shea, T.J. \& M.A. Bogan (eds.). Monitoring Trends in Bat Populations of the United States and Territories: Problems and Prospects. U.S. Geological Survey Information and Technology Report, Fort Belvoir, United States, 274pp.

Utzurrum, R.C.B. (1992). Conservation status of Philippine Fruit Bats (Pteropodidae). Silliman Journal (36): 27-45.

Walsh, A.L., C.M.C. Catto, T.M. Hutson, S. Langton \& P.A. Racey (2003). The United Kingdomnational bat monitoring programme: turning conservation goals into tangible results, pp. 103-118. In: O'Shea, T.J. \& M.A. Bogan (eds.). Monitoring Trends in Bat Populations of the United States and Territories: Problems and Prospects. U.S. Geological Survey Information and Technology Report, Fort Belvoir, United States, 274pp. 